\title{
Maracatu de Baque Solto: de brincadeira a patrimônio cultural
}

\author{
Maracatu of Baque Solto: from brincadeira to cultural heritage \\ Maracatu de Baque Solto: de brincadeira a património cultural \\ Giorge Patrick Bessoni e Silva \\ Instituto do Patrimônio Histórico e Artístico Nacional \\ (IPHAN), Brasil \\ giorgepbsilva@gmail.com
}

\author{
DOI: https://doi.org/10.18472/cvt.21n2.2021.1943 \\ Redalyc: https://www.redalyc.org/articulo.oa? \\ $\mathrm{id}=115468015011$
}

Recepción: 02 Junio 2021

Aprobación: 29 Julio 2021

\section{Resumo:}

O Maracatu de Baque Solto, bem reconhecido como Patrimônio Cultural do Brasil em 2014, é um bem cultural com características plásticas, cênicas, musicais e poéticas próprias, originado do contexto dos engenhos de cana-de-açúcar da Zona da Mata Norte do estado de Pernambuco. Sua culminância expressiva se dá no carnaval, embora seu calendário anual não se resuma, de modo algum, a esse período. Este artigo busca, pois, descrever e apresentar o Maracatu de Baque Solto e seu processo de patrimonialização. Esse bem cultural foi inscrito no Livro de Registro das Formas de Expressão e o processo de reconhecimento põe em cena aspectos culturais e simbólicos que vão além da expressividade do maracatu no carnaval, o que permite revelar um bem cultural que opera mecanismos e relações que abrangem variados aspectos da vida social. Assim, mais do que "folclore", ou uma manifestação cultural que se apresenta para o público no carnaval, o Maracatu de Baque Solto é parte constitutiva da vida cotidiana de comunidades do contexto canavieiro da Zona da Mata Norte pernambucana e das periferias de cidades da Região Metropolitana de Recife.

PALAVRAS-CHAVE: patrimônio imaterial, maracatu de baque solto.

\section{AbSTRACT:}

Maracatu of Baque Solto, recognized as a Cultural Heritage of Brasil in 2014, is cultural expression with its own plastic, scenic, musical and poetic characteristics, originated from the context of sugarcane mills in Zona da Mata Norte in tha state of Pernambuco. Its expressive culmination takes place in carnival, although its annual calendar is by no means limited to this period. This article seeks, therefore, to describe and present the Maracatu de Baque Solto and its patrimonialization. This cultural asset was inscribed in the Register of Forms of Expression, however, the recognition process brings into play cultural and symbolic aspects that go beyond the expressiveness of maracatu in carnival, which allows to reveal a cultural asset that operates mechanisms and relationships covering various aspects of social life. Thus, more than "folklore", or a cultural manifestation that is presented to the public at carnival, Maracatu de Baque Solto is a constitutive part of the daily life of communities in the sugarcane context of the Zona da Mata Norte in Pernambuco and the outskirts of cities in Pernambuco. Metropolitan Region of Recife.

KEYWORDS: intangible heritage, maracatu of baque solto, state.

\section{Resumen:}

Maracatu de Baque Solto, reconocido como Patrimonio Cultural de Brasil en 2014, es un bien cultural con características plásticas, escénicas, musicales y poéticas propias, originado en el contexto de los ingenios de caña de azúcar en la Zona da Mata Norte en el estado de Pernambuco. Su culminación expresiva tiene lugar en el carnaval, aunque su calendario anual no se limita en modo alguno a este período. Este artículo de disertación busca, por tanto, describir y presentar el Maracatu de Baque Solto y su patrimonialización. Este bien cultural fue inscrito en el Registro de Formas de Expresión, sin embargo, el proceso de reconocimiento pone en juego aspectos culturales y simbólicos que van más allá de la expresividad del maracatu en el carnaval, lo que permite develar un bien cultural que opera mecanismos y relaciones que abarcan diversos aspectos de la vida social. Así, más que "folklore", o una manifestación cultural que se presenta al público en el carnaval, Maracatu de Baque Solto es parte constitutiva de la vida cotidiana de las comunidades en el contexto cañero de la Zona da Mata Norte en Pernambuco y periferia de las ciudades de Pernambuco, Región Metropolitana de Recife.

Palabras ClaVE: património inmaterial, maracatu de baque solto, Estado. 


\section{INTRODUÇÃO}

O objetivo do presente artigo é descrever e apresentar o maracatu de baque solto e seu reconhecimento como Patrimônio Cultural do Brasil nos termos do Decreto n 3.551/2000[1]. Nesse sentido, faremos uma discussão acerca do maracatu tanto como expressão cultural, quanto como manifestação que opera outras forças da vida social, aspectos que o reconhecimento como patrimônio revela, para além de sua expressividade cultural conforme apreendida pelo público durante o carnaval, período do ano em que o bem cultural melhor se expressa para a sociedade. O artigo é resultado de pesquisas bibliográficas e de campo realizadas para a elaboração da dissertação de Mestrado "O que eu ganho com isso? Desafios da sustentabilidade econômica do patrimônio imaterial a partir do Maracatu de Baque Solto”, defendida pelo autor no âmbito do Mestrado Profissional em Preservação do Patrimônio Cultural do IPHAN em 2020 (Silva, 2020).

O Maracatu de Baque Solto, também conhecido como "maracatu rural", "maracatu de orquestra", "maracatu de caboclo", ou simplesmente "maracatu” e "baque solto", é uma manifestação cultural popular originária da Zona da Mata Norte de Pernambuco. É um bem cultural que chama a atenção por sua plasticidade, sua música e sua singularidade. Tem sido objeto de estudo de várias áreas das ciências humanas e das artes - como a antropologia, a história, o serviço social e as artes cênicas -, o que demonstra seu caráter polissêmico, a ponto de despertar interesses científicos e artísticos de pesquisadores de diversos campos do saber acadêmico. $\mathrm{Na}$ antropologia e na história, notadamente, foram investigados aspectos etnográficos (religiosidades, características culturais, significados simbólicos), trajetórias históricas e as relações com políticas públicas de grupos específicos (Medeiros, 2003; Sena, 2014; Romero, 2014; Esteves, 2016a) [2]; nas artes cênicas deu-se atenção às articulações entre particularidades culturais e aspectos cênicos, artísticos e estéticos (Martins, 2013). O que aproxima muito esses estudos e pesquisas é o fato de concentrarem suas análises em determinados grupos, determinadas trajetórias e experiência de vida de mestres e folgazões. Além desses, o inventário realizado para a elaboração do Dossiê de Registro do Maracatu de Baque Solto com vistas ao seu reconhecimento como Patrimônio Cultural do Brasil em âmbito federal (nos termos do Decreto $\mathrm{n}^{\mathrm{o}} 3.551 / 2000$ )[3] consiste em fonte das mais válidas, tendo em vista a amplitude de grupos pesquisados e as questões levantadas, que vão desde características socioeconômicas das localidades onde estão situados os grupos, a peculiaridades culturais e problemas e desafios para a sua sustentabilidade e salvaguarda[4], inserindo e discutindo recomendações de ações importantes para a garantia da continuidade das práticas culturais do maracatu, contemplando propostas de solução de problemas que os grupos de baque solto enfrentam. É a partir da descrição e das recomendações do Dossiê que o Iphan e o Estado brasileiro obtêm o conhecimento necessário para a atuação administrativa e jurídica quanto à preservação do Maracatu de Baque Solto.

Focando nos estudos mais recentes, eles analisam, dentro de sua matriz acadêmica, o baque solto como um todo, mesmo que partindo do caso de um grupo em particular, como o Maracatu Estrela de Ouro de Condado (Silva, 2015), o Maracatu Rural Cambinda Brasileira (Vieira, 2003; Martins, 2013), o Maracatu Cruzeiro do Forte (Sena, 2014) dentre outros trabalhos. Há também os que analisam o maracatu de modo geral, em contextos mais amplos, como a situação dos maracatuzeiros - e da brincadeira - no contexto da luta de classes da região da Zona da Mata Norte de Pernambuco (Medeiros, 2003) e as relações entre o maracatu de baque solto e o Estado (Esteves, 2016b).

Em finais do século XIX e inícios do XX, os Caboclos de Lança já eram figuras presentes nos canaviais da Zona da Mata Norte de Pernambuco. Versões sobre origens, por mais relevantes que sejam, não substituem o sentido que o bem cultural e a sua força simbólica têm para os detentores do presente. Sabe-se que, conforme acertadamente aponta Esteves (2016b), as expressões da cultura popular "são, na maioria das vezes, o resultado de múltiplas interlocuções, tensões e disputas históricas evolvendo (sic) os diversos atores sociais" (p. 2). Assim, o que se convencionou chamar de "Maracatu Rural”, "Maracatu de Baque Solto", ou simplesmente "maracatu" - como se referem muitos de seus brincantes - "parte mais da observação das 
práticas de seus integrantes e demais elementos que pareciam mais facilmente visíveis, do que propriamente dos múltiplos sentidos e da experiência de seus participantes" (Idem, ibidem).

Juntamente com esses estudos, figura aquele que tentou reunir, de maneira sistemática e com foco na possível patrimonialização daquele bem, questões históricas, culturais, territoriais e documentais acerca do maracatu de baque solto. O Inventário Nacional de Referências Culturais do Maracatu de Baque Solto[5] foi uma pesquisa que durou mais de dois anos; promoveu a reunião dos estudos clássicos do tema com vasto levantamento bibliográfico, com a atualidade da pesquisa etnográfica mediante entrevistas, visitas de campo, debates com detentores e produção de considerável material fotográfico e audiovisual. Teve como objetivos - os de praxe para o INRC - reunir informações que possibilitassem formar um discurso patrimonial, a ser analisado pelos técnicos do Iphan - em Pernambuco e em Brasília - e posteriormente pelos membros do Conselho Consultivo do Patrimônio Cultural no sentido de torná-lo Patrimônio Cultural do Brasil.

\section{O BAQUe SOlto PATRIMÔNIO CULTURAL: PROCESSOS DE RECONHECIMENTO}

A patrimonialização de um bem cultural de natureza imaterial é, tecnicamente, instruída no âmbito do IPHAN, quando se trata de reconhecimento de patrimônio cultural em nível federal. As regras que norteiam tal processo estão estabelecidas no Decreto federal n ${ }^{\circ} 3.551 / 2000$, que institui o Registro desses bens culturais e cria o Programa Nacional do Patrimônio Imaterial - PNPI, instrumento de política pública para pesquisa, reconhecimento e apoio e fomento ao patrimônio imaterial. Os bens culturais de natureza imaterial sofrem, nesse processo, uma classificação teórica, com vistas à definição do bem cultural e inscrição em um dos Livros de Registro. São quatro livros: Celebrações, Formas de Expressão, Saberes e Lugares (Brasil, 2000). Assim, o processo de pesquisa e identificação, bem como de descrição de aspectos culturais e construção de uma narrativa patrimonial buscam a classificação do bem cultural em uma das categorias com vistas à inscrição no Livro de Registro. Tal categorização em geral escapa as definições e aos valores sobre os bens atribuídos pelas próprias comunidades detentores, o que instaura uma construção de sentido oficial, com o objetivo de reconhecimento patrimonial no âmbito do Estado.

Assim, entendemos o processo de patrimonialização a partir da definição de patrimônio cultural da Constituição Federal de 1988, segundo o qual:

Constituem patrimônio cultural brasileiro os bens de natureza material e imaterial, tomados individualmente ou em conjunto, portadores de referência à identidade, à ação, à memória dos diferentes grupos formadores da sociedade brasileira (IPHAN, 2006).

Compreendemos a patrimonialização também como um projeto de valorização da diversidade cultural, capaz de fomentar, por meio do reconhecimento de elementos e referências culturais de determinadas comunidades e grupos sociais, desenvolvimento e cidadania (Silva, 2011; Lemos et al., 2018).

O processo de Registro do Maracatu de Baque Solto foi aberto no âmbito do Iphan em 2008, com o título "Encaminha/documentação para abertura do processo de Registro no Livro Formas de Expressão do Maracatu Rural/ como Bem Cultural do Brasil de natureza imaterial”[6]. Logo de início percebe-se que a intenção foi reconhecer o maracatu de baque solto como Forma de Expressão, inscrevendo-o no Livro de Registro de mesmo nome. Conforme o Decreto n ${ }^{\circ} 3.551 / 2000$, em seu Artigo $1^{\circ}$, serão inscritos nesse livro "manifestações literárias, musicais, plásticas, cênicas e lúdicas". Assim, logo se depreende que os aspectos expressivos do bem cultural foram ressaltados, em detrimento de seus aspectos celebrativos - visto que o bem cultural possui, também, a nosso ver, uma característica festiva muito presente[7].

O primeiro pedido de reconhecimento do baque solto foi promovido pelo então Governador de Pernambuco, Eduardo Campos, em ofício enviado ao então Ministro da Cultura, Gilberto Gil, no qual menciona, além do maracatu rural, o maracatu nação, o caboclinho e o cavalo marinho como "marco da dança popular pernambucana e brasileira" [8]. Em avaliação técnica preliminar sobre a documentação 
entregue pelo Governo de Pernambuco para o pedido de Registro do Maracatu Rural, a equipe técnica da Superintendência do Iphan em Pernambuco enfatiza o caráter híbrido do maracatu de baque solto, resultado da fusão de diversos elementos da cultura popular da região. O Departamento de Patrimônio Imaterial do IPHAN (DPI/IPHAN), por sua vez, endossa a visão do Maracatu de Baque Solto como Forma de Expressão, embasado na argumentação segundo a qual os elementos que se sobressaem no bem são aqueles cênicos, musicais, poéticos.

Assim, a brincadeira Maracatu de Baque Solto tornou-se patrimônio cultural. De acordo com o Decreto federal $n^{\circ} 3.551 / 2000$, inscrever um bem cultural nesse livro de Registro implica reconhecer seus aspectos expressivos, cênicos, lúdicos, que se refletem, no caso do Baque Solto, em seus aspectos plásticos - fantasias, cores, manobras, cortejo etc. -, musicais, poéticos. No entanto, embora tais aspectos são os que mais saltem aos olhos do grande público, sobretudo no carnaval, eles se referem a uma parte apenas do que consiste de fato esse bem cultural. Baque Solto é mais que isso: é sentimento de comunidade, é religião, são relações sociais. E tais aspectos são revelados no próprio processo de patrimonialização: o Dossiê que resulta do inventário produzido para instrução técnica do processo de Registro traz questões que vão para além do maracatu como forma de expressão, as quais estão enraizadas no cotidiano das comunidades que detêm o bem cultural - os detentores, no jargão utilizado no âmbito do Iphan. Tais aspectos serão descritos neste artigo.

\section{3. "Botar O MARACATU NA RUA": CARACTERísticas SOCIOCUlturais do Maracatu De BaQue Solto}

Essa expressão cultural, resultado de encontros e interpretações múltiplas, reúne elementos de música, dança, arte, religiosidade, comunidade, sociabilidade, poesia. Brinquedo sério dos trabalhadores e trabalhadoras da Zona da Mata Norte de Pernambuco e de bairros periféricos de cidades da Região Metropolitana do Recife.

Para os folgazões, maracatu de baque solto é brincadeira, folguedo, brinquedo. Tem presença marcante na paisagem dos latifúndios de cana-de-açúcar da Zona da Mata Norte de Pernambuco e na Região Metropolitana do Recife, por força da imigração que o fenômeno do êxodo rural legou para essa região. Apresenta-se durante boa parte do ano, de diversas maneiras: no carnaval, com o cortejo completo, no Concurso de Agremiaçóes Carnavalescas do carnaval do Recife, e no circuito de polos do Governo de Pernambuco; nas sambadas e nos ensaios, evolui nos terreiros de origem dos grupos e dos detentores, a maioria cortadores de cana.

Historicamente, o maracatu de baque solto surgiu nos momentos de festa dos trabalhadores da cana-deaçúcar dos engenhos pernambucanos. Para dançar, festejar e sambar, os canavieiros improvisaram ritmos a partir dos próprios instrumentos de trabalho. Improvisaram também poesia, arte que persiste até os dias atuais. Segundo Vieira e Silva (2007):

\footnotetext{
Inicialmente, o maracatu era brincado apenas nos engenhos e - de engenho em engenho - os deslocamentos eram feitos a pé. Seus componentes, durante o carnaval, eram alimentados pelos próprios moradores e posseiros, que os recebiam, acomodando a brincadeira nas casas coletivas de farinha. Em suas apresentações originais, eles levavam consigo a identidade de pertencimento a uma nação, uma tribo, perfigurada na bandeira (hoje chamada estandarte), símbolo identitário do grupo. Essa manifestação cultural - simplesmente chamada maracatu (...) - somente começa a ser enxergada na "rua" (ou seja, pelos moradores das cidades interioranas da Mata Norte de Pernambuco) no início do século XX (p. 3).
}

Personagens do maracatu como o Caboclo de Lança são encontrados em relatos já no final do século XIX. Conforme memórias, eles teriam sido conhecidos pelo nome de "mulungus", isto é, "coisa de caboclo". Os Caboclos de Lança geralmente causavam medo quando apareciam nos povoados e cidades, sozinhos ou em duplas, e não raro provocavam arruaças e brigas entre si - cabe ressaltar que o termo "maracatu" também significava bagunça, confusão (Sena, 2014).

Segundo o Dossiê do INRC do Maracatu de Baque Solto, existem cerca de 115 grupos atuantes, espalhados por vinte e quatro cidades, sendo dezesseis na Mata Norte. Com as referidas correntes migratórias, que 
levaram trabalhadores para as cidades da Região Metropolitana do Recife em meados do século XX, o maracatu de baque solto também passa a se fazer presente em cidades como Camaragibe e Olinda (idem, p. 35-36).

O maracatu de baque solto chegou ao Recife e sua Região Metropolitana devido ao êxodo rural da população dos engenhos canavieiros, a partir dos anos 1930. Bairros como Torrões (em Recife) e Cidade Tabajara (em Olinda) passaram a abrigar grupos de maracatu. Conforme bem observa Sena (2014), esses bairros, juntamente com outros das periferias de Recife, Olinda e outros municípios da RMR abrigam um grande número de maracatus provenientes do interior de Pernambuco. Grupos como o Maracatu Cruzeiro do Forte (Recife) e Maracatu Piaba de Ouro (Olinda) são exemplos dessa transformação - e resiliência cultural após a migração de trabalhadores do contexto da cana.

$\mathrm{Na}$ brincadeira do maracatu rural, os participantes ou integram a parte musical/poética - Mestre do Apito, Contramestre, Terno e músicos de sopro -, ou "vestem figura", isto é, encarnam um personagem do folguedo. "Figura" é o termo dado pelos folgazões aos personagens que compõem o baque solto, de modo que "vestir figura" é encarnar - palavra que a nosso ver expressa melhor o que eles fazem do que "encenar" - o personagem. Assim, cada integrante possui uma função específica a contribuir com sua figura para a harmonia do brinquedo, a fim de que as apresentações ocorram sem "desmantelo", em absoluta paz (Martins, 2013).

Na hierarquia desse bem cultural, quem comanda a brincadeira é o Mestre do Apito: porta-voz do grupo, é a figura que deve dominar o ofício de poeta. É ele quem ordena as manobras e evoluções dos demais personagens no cortejo e quem, nas apresentações de carnaval, executa as tradicionais marchas de abertura, marchas de saída e marchas de chegada. De acordo com Martins (2013), o mestre "ao entoar suas loas instaura o silêncio na festividade" (p. 15). Com seu apito e sua batuta - bengala decorada com anéis - ele rege o maracatu, determinando o momento de os folgazões e músicos pararem para ouvir seus versos, assim como o de retorno da música e das manobras. Fora do período carnavalesco, comanda as outras celebrações que fazem parte do calendário do Maracatu de Baque Solto: é o mestre do apito quem dá as ordens nas festas dos ensaios e das sambadas[9].

O Caboclo de Lança - ou Caboclo de Vara, ou ainda Caboclo de Guiada - é a figura mais icônica do maracatu de baque solto; a que representa o bem cultural no imaginário popular e nas propagandas turísticas - simboliza a identidade do povo pernambucano e seu carnaval multicultural. É, de fato, uma figura exuberante. Tem por função proteger o seu grupo nas apresentações, delimitando o espaço entre o maracatu que representa e o público. É ricamente vestido, em termos visuais: um chapéu alto feito de palha e coberto de papel celofane de diversas cores, de acordo com seu guia espiritual; um lenço que lhe envolve a cabeça, e no qual é costurado o chapéu; o rosto pintado de vermelho (com uso do urucum); uma gola, desenhada com diversos motivos - de desenhos simétricos a brasões de clubes de futebol, animais, o que a imaginação mandar fazer, tudo feito com lantejoulas coloridas costuradas em tecido de veludo - que vai do pescoço até os joelhos, de largura que ultrapassa os ombros do folgazão, decorada nas bordas com franjas coloridas; calças chamadas de fofa, que ficam por cima do ceroulão e são feitas de chita com elástico nas pernas até a altura dos joelhos, também decoradas com franjas; meiões esticados até a barra da calça e sapatos; o surrão, impressionante aparato de madeira e coberto de lá que fica amarrado pelos ombros e pela cintura às costas do caboclo e no qual são presos chocalhos de boi, em quantidade variável (sempre ímpar, para não atrair azar), podendo pesar até quinze quilos e atingindo a altura das nádegas[10]. Toda a roupa é pensada para as manobras do maracatu, sua beleza, sua sonoridade e o destaque do caboclo de lança como guerreiro (Barbosa, 2018).

O Caboclo porta a sua guiada, ou vara, ou lança, que é feita de madeira firme (que pode ser de imbiriba ou de quiri), medindo cerca de dois metros de altura, levemente pontuda na extremidade que fica para cima, e decorada em toda a sua extensão com fitas de pano coloridas. Importante observação sobre o caboclo de lança é feita por Vieira e Silva (2007), observação essa que destaca a apropriação da figura do caboclo de lança para além da brincadeira: 
[...] na última década, o caboclo de lança transcendeu o ambiente originário de sua cultura (ou subcultura) periférica e ganhou o palco central das representações sociais "típicas" do imaginário pernambucano. Esse fenômeno só tem razão de ser - por hipótese - em função do largo incentivo motivado pelas políticas públicas e pela mídia local: imprensa escrita, televisiva, publicidade e propaganda oficial (p. 1).

Nesse contexto, o caboclo de lança é convertido em ícone da pernambucanidade, juntamente com o passista de frevo, ou o batuqueiro e a rainha do maracatu nação, em um processo que revela o contato mútuo entre a cultura popular, a cultura "oficial" - aquela valorizada pelas políticas públicas como símbolo de identidade territorial - e a cultura de massa. A patrimonialização desse bem cultural - e, mais precisamente, a leitura que a política pública federal de salvaguarda desse patrimônio faz do bem a partir de quando ele se torna oficialmente protegido - coloca um ponto a mais nesse universo intrincado, que se expande para além dos momentos da performance da brincadeira e do contexto territorial da maioria dos grupos de maracatu - a região canavieira da Zona da Mata Norte de Pernambuco -, embora se tenha sempre que voltar a ele quando da análise do que acomete ao maracatu em termos de política pública. O fato é que, sendo secular, o caboclo de lança - e junto com ele o maracatu de baque solto - foi convertido nos últimos 30 anos de um personagem marginal da cultura popular para "símbolo maior do nosso carnaval que, por extensão, carregaria em si os traços ancestrais de uma alma/cultura genuinamente pernambucana” (Vieira; Silva, 2007, p. 2).

Os Caboclos de um maracatu representam os guerreiros, e nas apresentações ocupam posições como se formassem uma tropa. E eles têm um chefe: é o mestre caboclo. Ele comanda seus guerreiros indo no centro da fila de Caboclos que abre caminho para o maracatu passar: são quatro caboclos dispostos nessa fila; em cada lateral, seguem também filas de Caboclos de Lança, protegendo os demais membros do grupo, formando "uma cerca humana de proteção", nas palavras de Silva (2012, p. 46). O Mestre Caboclo tem a função de comandar a evolução dos lanceiros durante a apresentação do maracatu: seus movimentos devem ser seguidos por outros caboclos enquanto o grupo manobra. Nas extremidades dos cordões ficam os Caboclos-Guias, e dando-lhes cobertura, os Caboclos Boca de Trincheira. Em alguns grupos, dois Caboclos de lança aparecem ao final do cortejo, fora de linha, aparentemente soltos, mas que na verdade estão oferecendo cobertura simbólica para eventuais ataques pela retaguarda (Silva, 2012, idem).

No maracatu de baque solto há um personagem Caboclo, mas que não usa lança: em seu lugar, um machado; e seu chapéu é um cocar frondoso coberto de penas de pavão. É o Caboclo Arreiamá, ou Caboclo de Pena. Representa os índios no maracatu, a ligação com as forças sagradas da natureza.

Fala-se em cortejo para o maracatu porque, assim como seu irmão maracatu nação, tem uma corte real. Até os anos 1930, 1940, os maracatus de baque solto não possuíam corte: essa tradição sempre esteve historicamente ligada ao maracatu nação, cuja representação cênica é da coroação de reis e rainhas de Congo. Mas a partir de exigências da Federação Carnavalesca de Pernambuco - FECAPE para participar do concurso de agremiações do carnaval do Recife, o maracatu da zona da mata, o rural, teve de adotar esse cortejo, nos mesmos moldes do maracatu de baque virado. Os maracatus, com menos visibilidade social à época e ainda bastante associados a "coisas de arruaceiros", de "vagabundos", necessitando de legitimidade social e política perante as autoridades, intelectuais e demais apreciadores do carnaval da capital de seu estado, aceitaram essa imposição e se adaptaram à nova regra (Silva, 2012; FUNDARPE, 2013; Esteves, 2016a). Desse modo, os personagens cortesãos foram sendo consolidados na tradição do bem cultural, e alguns de seus componentes passaram a possuir relevância significativa para os sentidos e significados religiosos, espirituais e simbólicos do baque solto, de maneira que sem eles de modo algum um grupo de maracatu pode sair para o carnaval.

Essa corte remete ao imaginário do cortejo real francês: possui um Rei e uma Rainha; o Príncipe, a Princesa e o Pajem; a Dama do Buquê e seu Cavaleiro, o Valete, a Dama do Paço, os Carregadores do lampião e do símbolo do maracatu (na maioria das vezes, o objeto ou animal que dá nome ao seu grupo - estrela, chuva, cruzeiro; leão, cambinda, carneiro, pavão, pantera, águia, piaba (peixe de água doce), beija-flor, burra, pinguim, gavião, camelo) (Silva, 2012, p. 54-55). 
A Dama do Paço é encarnada por uma mulher, que deve estar "pura”, ou seja, sem relações sexuais e outros interditos religiosos por determinado período. É ela a responsável por cuidar da calunga - a boneca sagrada, que representa entidades espirituais protetoras, e está presente tanto no maracatu de baque solto quanto no maracatu nação - e por isso também é conhecida como "Dama de Boneca". Somente a ela é dada permissão e autoridade - para ter acesso à boneca nos períodos de apresentação. Nessas ocasióes, a Dama do Paço carrega e desfila com a boneca. Por ser a portadora de um elemento importante de proteção espiritual e religiosidade no maracatu de baque solto, a dama do paço é função de grande responsabilidade. Sabe-se que a calunga boneca que pode ser feita de madeira, ou cera, ou outros materiais - "concentra o poder espiritual do grupo" de maracatu (Sena, 2014). Assim, ela contribui para proteger os folgazões e impedir mandingas e malfeitos de outros grupos, ou dificuldades que possam ser encontradas no longo trajeto de três dias de viagem durante o carnaval[11]. Por carregar tamanha responsabilidade, a Dama do Paço deve ser, portanto, iniciada na Jurema (Sena, 2014).

Também integra o contexto a ala de Baianas. Inicialmente, como eram proibidas mulheres nos maracatus, homens vestiam essa fantasia. Com o passar do tempo, por volta dos anos 1950, mulheres puderam integrar os grupos, e foram naturalmente assumindo esse personagem, assim como o de Rainha (Silva, 2012). Essa questão levantou, ao longo do tempo, reflexões e debates em torno da questão de gênero e da participação da mulher no baque solto.

O Bandeirista, ou Porta-Estandarte ocupa, também, posição destacada no maracatu de baque solto. É que apresenta o grupo, com seu pendão, para o público. A bandeira é objeto que carrega intenso significado, pois representa toda a nação do maracatu: é nela que estão inscritos o nome, o símbolo, o ano e o local de fundação. É aos seus pés que os caboclos de lança se ajoelham e prestam reverência quando chegam para se juntar ao seu grupo.

Um personagem importante para se pensar sobre os aspectos econômicos de sustento e sustentabilidade do maracatu de baque solto é a Catita. Geralmente homem vestido de mulher, porta uma cesta e graceja de diversas formas perante o público, na rua, durante as apresentações. Vem à frente do grupo, acompanhando a Burrinha, que abre espaço na multidão com seu chicote para que o maracatu possa fazer suas manobras. A Catita tem o rosto pintado de preto, sua roupa é simples, leve: vestido. Ela tem por função, junto com o Mateus[12] conseguir os meios materiais - dinheiro, comida e bebida - com os quais os folgazões vão garantir a saciedade de fome e sede no período carnavalesco, sempre marcado por longas viagens. Ela, antigamente, segundo contam com alegria e graça os folgazões, chegava a roubar as casas dos terreiros onde o maracatu brincava. Pudemos colher relatos que dão conta de que as catitas iam fazendo graça para a multidão, chamando a atenção para si; quando o maracatu entrava e começavam as manobras e músicas, ela aproveitava que o povo estava concentrado na apresentação, dirigia-se até os fundos das casas, que geralmente tinham as portas destrancadas - eram tempos de pouca ou nenhuma precisão de chave, grades ou cadeados para segurança do lar - e aproveitava para sair com punhados de farinha, carnes, frutas, tudo o que pudesse encontrar de fácil alcance. E guardava na cesta, para depois os demais folgazões poderem comer, fortalecendose depois de um dia de festejos pelos engenhos e ruas, e também para suportarem mais viagens que o dia seguinte guardava. Atualmente, além das brincadeiras e interações com a plateia - piadas, abraços, cantadas em homens acompanhados de suas respectivas, beijos - a Catita pede dinheiro, um gole de cachaça, uma comida - qualquer coisa que seja de fácil alcance para o provável doador.

Outros personagens populares também fazem parte de grupos de baque solto, como a Burrinha, o Mateus, o Bicheiro e o Caçador. Figuras que compõem a realidade sociocultural das populações da zona canavieira da Mata Norte de Pernambuco (Silva, 2012).

As histórias dos indivíduos e dos grupos de maracatu de baque solto guardam estreita relação com o ambiente sociocultural da Zona da Mata Norte de Pernambuco. Essa mesma relação é mantida pelos folguedos populares da região; assim, o maracatu rural está fortemente vinculado a outras manifestações como o coco de roda, a ciranda, o cavalo marinho, bens culturais dos ciclos junino e natalino. Uma explicação 
para tal relação reside no fato de que a região da Mata Norte, fortemente rural, guardou por bastante tempo certo isolamento social em relação à Região Metropolitana do Recife, de modo que essas expressões da cultura popular eram talvez as únicas formas de lazer e entretenimento das populações locais. Os engenhos canavieiros seguiam a convenção social de reservar lotes de terras para que famílias de trabalhadores vivessem no latifúndio, prática que surgiu com o fim da escravidão no Brasil. Esse contexto permitiu que se construísse e se desenvolvesse uma relação tão visceral dos indivíduos com a brincadeira do maracatu que, mesmo em contextos fora da Mata Norte e em meio urbano, ela se mantém viva.

Assim, embora surjam nuances, modificações no modo de organizar-se e exibir-se, os maracatus de baque solto oferecem repertórios culturais identificáveis ao longo do tempo, corroborando a necessidade, até, de adaptações, a fim de que se mantenha a vivacidade do folguedo e, consequentemente, persista o caráter de memória longa desta forma de expressão. É nessa dinâmica, portanto, que personagens, e respectivos figurinos, mantêm-se conforme pede o apreço de folgazões pelos conteúdos tradicionais [...] (FUNDARPE, 2013, p. 47).

Quanto à composição musical, os instrumentos que formam o conjunto do maracatu de baque solto, denominado terno, são basicamente os mesmos catalogados pelo pesquisador Guerra Peixe na década de 1950: de percussão, gonguê, ganzá, tarol, cuíca (ou poica[13], no linguajar local dos detentores), bombo ou surdo; e de sopro, trombone, trompete, saxofone e clarinete. Em alguns poucos grupos, ainda se encontra o instrumento chamado buzina, feito de flandres e que antigamente era tocado pelo mestre tirador de loas; atualmente, é tocado por um dos músicos do terno. O terno preenche de música uma poética rica e em constante alimentação[14].

A poesia do maracatu de baque solto é feita de improvisos. Claro que existem os sambas antigos, que são repetidos por diversos mestres. Mas é visto como um valor dentro do maracatu o fato de os mestres improvisarem o versejar. Nesse sentido, a poética do baque solto está em estreito diálogo com a de outras tradições culturais, como o coco, o repente, o cordel e o cavalo marinho (FUNDARPE, op. cit., p. 72). Uma poética, popular, anima a outra. Aliás, a sintonia entre o baque solto e o cavalo marinho é evidente: muitos brincantes de um folguedo participam do outro; alguns mestres de cavalo marinho são lideranças de maracatus de baque solto, fato notado em pesquisas acadêmicas (Silva, 2015). A importância da poesia para o baque solto se reflete na existência de encontros de mestres para desafios poéticos; como nas sambadas, descritas mais adiante.

O maracatu de baque solto é um folguedo do ano todo. Mas sua culminância, digamos, ritualística é o carnaval. Embora alguns maracatuzeiros afirmem que no carnaval o que os foliões e turistas veem corresponde a uma amostra pequena do que é o maracatu - e as observações de campo mostram que a afirmação é procedente[15] - é nele que os grupos se apresentam de maneira completa, ou seja, com todas as fantasias, com cortejo, com personagens. Os rituais que perfazem o calendário anual do brinquedo são, principalmente, a meu ver, a sambada, o carnaval e o carnaval de Páscoa.

A sambada é realizada nos meses que antecedem o carnaval. São eventos onde se apresentam "à paisana” os personagens dos maracatus; geralmente abertos ao público, ocorrem tanto nos seus espaços próprios - os terreiros[16] - quanto nas cidades. Consiste, em síntese, em um momento onde as habilidades dos mestres de maracatu de caboclos de lança são postas à prova. Um grupo de maracatu, geralmente o promotor do evento, convida outro grupo para a sambada. Esse convite pode ser compreendido como um desafio, cuja sambada é o palco. Todos os ritos da festa - que, de costume, dura a madrugada inteira - estão eivados de desafio entre os dois (ou mais) grupos participantes. Em conversas informais que tive com folgazões em ocasiões de sambadas, fui informado que se o grupo convidado chega ao local da festa primeiro do que aquele que a está organizando, este já começa "perdendo".

Assim se inicia o ritual da sambada: o mestre do maracatu organizador começa os versos, cantados em marchas, de improviso, incitando os caboclos e demais presentes para que aproveitem a festa e que não haja violência entre os brincantes e folgazões. Posteriormente, passa, também em versos cantados de improviso, a pedir que a plateia e demais presentes forneçam bebida e comida aos integrantes do maracatu. $\mathrm{O}$ mesmo 
faz, posteriormente, o mestre do grupo de maracatu convidado. Cada grupo a seu tempo, então, para a fim de beber e comer, enquanto o outro passa a cantar de improviso, sempre acompanhado pelo terno da brincadeira. Após esses ritos, que duram talvez mais de uma hora, começam os desafios mais explícitos. Como sempre, o mestre do grupo organizador não pode permitir que o mestre do grupo convidado inicie o desafio, porque senão novamente sai "perdendo". Nesse momento, os versos passam a ser cantados em samba curto, samba comprido, samba de dez ou em galope, e o conteúdo passa a ser mais voraz, podendo envolver inclusive insultos pessoais ao mestre "adversário". Acompanhados cada um de seu terno, os mestres seguem improvisando durante toda a madrugada, e os caboclos de lança e demais personagens dançam livremente, executando pernadas, rasteiras, volteios, manobras que nem sempre conseguem executar durante as apresentações de carnaval, dado o peso e o tamanho das fantasias, bem como o curto tempo que geralmente têm as apresentações. Essas festas ocorrem sob clima de provocações e chistes, onde desafio e camaradagem convivem e configuram o sentido desse complexo ritual. Sobre a dinâmica das sambadas, Esteves esclarece (2016b, p. 7-8):

Nos dias de sambada, percebe-se que os demais integrantes do maracatu costumam participar gratuitamente e chegar acompanhados de suas famílias. Nestas ocasiões, se reúnem próximo ao botequim montado pelo dono do maracatu ou mesmo em determinados espaços do terreiro para rever os amigos e conhecidos e sambar maracatu. Antes de serem iniciadas as atividades, observa-se que em alguma sedes há o costume de serem executadas cirandas, cocos e outros ritmos. Na oportunidade, ocorre também o recrutamento de novos membros, bem como a iniciação de algumas crianças no universo do maracatu, por meio da observação dos mais velhos.

As sambadas são ocasiões importantes de repasse de saber e manutenção e atualização das tradições do Maracatu de Baque Solto. Ainda com Esteves (2016b, p. 8-9):

Passado certo tempo de samba, sobretudo nos esquentes de terno que antecedem os dias de carnaval (também chamados de
ensaio de carnaval), por vezes, o mestre caboclo passa a conduzir as manobras dos folgazóes, fazendo com que os caboclos
mais experientes tomem à frente dos cordões e os mais jovens e crianças sigam seus movimentos, observando e aprendendo
a sambar a partir da prática. Nestas ocasióes, as baianas passam a formar um cordão interno paralelo ao dos caboclos e os
integrantes da corte ocupam uma posição central, protegidos pelos dois cordões.

Conforme esse pesquisador (2016b, p. 6), quando a festa é promovida no terreiro do maracatu que está organizando o evento, é o próprio dono do maracatu que deve arcar com as despesas para a sua realização, as quais envolvem principalmente bebidas, comidas e pagamento aos folgazóes. Quando a sambada ocorre no terreiro ou sede de outro maracatu, existe uma espécie de "acordo tácito", segundo o qual o grupo que está organizando o encontro deve arcar com parte das despesas também da agremiação convidada. A sambada tem um caráter de competição: os grupos competem, por meio dos versos improvisados dos mestres com o desejo de vencer o oponente na sambada. Nessa poesia, acompanhada com entusiasmo pelos folgazóes, que reagem com gritos de alegria a cada estrofe entoada por seu mestre, há provocações, chistes, perguntas que o oponente deverá responder, revidar, superar.

Em certas situações, o dono do maracatu que promove a festa recebe apoio de prefeituras, de políticos como vereadores e deputados, do governo estadual e de outros órgãos públicos. Essa dinâmica revela certo caráter de espetacularização que tem ocorrido em algumas sambadas, fato que coloca um viés de empreendedorismo ao evento (Esteves, 2016b, p. 7). Em sambada realizada em novembro de 2017 em Nazaré da Mata, observamos que havia, inclusive, um locutor que anunciava, em tom triunfal, as chegadas dos maracatus, fazia agradecimentos e interagia com a plateia. Fogos de artifício, cobertura policial e banheiros químicos também faziam parte da estrutura da festa, o que geralmente não costuma haver quando se trata de um evento mais tradicional. De fato, essa sambada a que me refiro contou com o apoio da prefeitura municipal e da Secretaria de Cultura do governo do estado.

O poder público por vezes contribui financeiramente com o encontro. O governo estadual, a prefeitura ou mesmo políticos prometem, por exemplo, apoio financeiro para contratação de ônibus para levar e trazer os folgazões, para pagamento ao mestre, ao terno e aos músicos, contratação de carro de som ou aluguel de amplificadores ou, simplesmente, garantem uma 
melhor iluminação com gambiarras no terreiro, limpeza e capinação no local onde será realizada a sambada (Esteves, 2016b, p. 7).

Em geral, o dono do maracatu organizador da sambada costuma montar uma venda para arrecadação de dinheiro por meio da comercialização de comidas e bebidas. Parte desse dinheiro vai para pagamento das despesas do evento. Outra forma de arrecadar dinheiro nas sambadas é por meio de homenagens e menções que os mestres fazem, de forma poética improvisada a certas pessoas presentes, as quais devem retribuir, segundo o costume, com dinheiro, ou bebidas, ou comidas para os folgazóes.

As sambadas terminam, via de regra, ao raiar do dia seguinte, quando o mestre "bate o terno".

Como uma espécie de rito de passagem, a sambada só se encerra quando o mestre pede para "bater o terno" pela última vez no início da manhã e os folgazões retornam todos ao terreiro para a realização das últimas manobras. Até que, por fim, podem retornar às suas casas, prontos para brincar o carnaval (Esteves, 2016b, p. 9).

No carnaval os grupos costumam desfilar pelos municípios da zona da Mata Norte, no Concurso de Agremiações do Recife e no Encontro Estadual dos Maracatus de Baque Solto de Pernambuco. Nessa ocasião os grupos vão, como dito anteriormente, paramentados, apresentam seu cortejo e suas manobras - nome dado aos passos e movimentos dos personagens - e concorrem entre si por prêmios. Essa concorrência se dá, especificamente, no Concurso do carnaval do Recife, onde, divididos por Grupos - Especial, Acesso etc. - os grupos desfilam no percurso estabelecido pela Prefeitura do Recife, e recebem notas de jurados que medem o cumprimento de regras específicas, em geral discutidas antes do carnaval por diversas instâncias, com participação de representantes dos grupos. Os prêmios são em dinheiro, e além disso os grupos recebem uma subvenção para participar do Concurso. Nem todos os grupos atualmente existentes dele participam.

Nas cidades do interior, os grupos que desfilam também recebem subvenção das prefeituras que os convidam. A principal cidade é Nazaré da Mata, onde o encontro de maracatus de baque solto é evento tradicional do carnaval local, e apreciado por numerosa quantidade de pessoas - moradoras da área urbana, da zona rural, de cidades vizinhas e turistas.

O carnaval de Páscoa é o evento, o rito, que mostra a vinculação do bem cultural à fé católica. Segundo o Dossiê do INRC do Maracatu de Baque Solto (FUNDARPE, 2013, p. 84):

O Carnaval de Páscoa é uma celebração que se dá com almoço festivo, no domingo de páscoa, e simboliza o encerramento das comemorações do ciclo carnavalesco. A principal motivação é reunir os folgazões, na própria sede ou em algum outro espaço coletivo, para interagir, confraternizar, celebrar a tradição, inclusive a tradição cristã.

Trata-se de uma celebração de fundo simultaneamente religioso e profano, na qual a música, a dança e a poesia do maracatu são executadas em agradecimento pelo período carnavalesco, e também em respeito a uma das datas mais importantes do Cristianismo: a ressurreição de Jesus Cristo. A poesia de improviso mais uma vez se faz presente, ao som tradicional das marchas e dos sambas de maracatu. Alguns grupos saem percorrendo ruas e logradouros cujo percurso atende à necessidade de se prestar reverência frente a algum templo católico nas proximidades onde se faz a festa. Já outros festejam no local sem esse percorrer. A festa do carnaval de Páscoa se assemelha à das sambadas, visto que os folgazões não saem paramentados como no carnaval. Mais uma vez, o carnaval de Páscoa também é elemento relevante a ser considerado na sustentabilidade do bem cultural. Conforme o Dossiê (FUNDARPE, 2013, p. 87):

Caboclos, baianas, catitas, mateus, burra, arreiamá são convocados e se integram à comemoração, o que, por vezes, gera cachê e custos de deslocamento a serem pagos pela agremiação. E justamente os gastos com a festividade é que têm sido motivo para a diminuição da ocorrência. Alguns grupos [...] não têm conseguido recursos para a celebração pascal, a não ser dos brincantes e de um e outro comerciante.

Quanto ao aspecto religioso, tem-se, nos rituais e nas atividades cotidianas, o respeito e a veneração ao culto da Jurema, ou Jurema Sagrada, ao Candomblé, e o sincretismo com o catolicismo popular, o que se reflete em diversos aspectos da brincadeira, desde alguns personagens - como o Caboclo de Lança e o Caboclo de Pena 
- às bonecas, ou Calungas, que são revestidas de poder espiritual e só podem ser carregadas nas apresentações pelas Damas do paço, às casas de mestres e brincantes, que apresentam referências a esses cultos religiosos. Cada grupo de maracatu de baque solto se relaciona de maneira peculiar com a religiosidade, sobretudo a Jurema, e este ponto tem muito de segredo - algumas questões não são expostas para a sociedade em geral, estrategicamente. Certo é que todo grupo deve se proteger espiritualmente, ou estar "calçado", conforme é dito no falar nativo. E isso se faz por meio de rituais da Jurema, do Candomblé (em terreiros que geralmente façam também culto sincrético aos mestres e caboclos) ou da Umbanda.

Nas interlocuções com os detentores do baque solto, o assunto religião sempre é mencionado, tratado com deferência, seriedade e orgulho. $\mathrm{O}$ respeito aos ritos e obrigações religiosas é capital para se ter paz e harmonia, para ficar protegido. Ouvimos histórias de ônibus que se quebraram em deslocamento para apresentações no Recife por causa de um "calço" mal feito. Interditos religiosos e o calço também atingem membros folgazões, antes e durante o carnaval. Embora se fale bastante no assunto, essa questão tem vários aspectos e nuances nunca revelados para não folgazóes, ou mesmo para brincantes que não se interessem muito por seguir tais rituais. A relação com as entidades espirituais faz parte do segredo do maracatu.

Trata-se do preparo religioso que antecede e sucede as apresentações, inclusive as sambadas e o período carnavalesco. Essas preparações geralmente são realizadas por pessoas específicas: o padrinho ou madrinha espiritual da brincadeira, e impedem o "desmantelo" da mesma, ou seja, funcionam como uma proteção para que não ocorram incidentes, brigas ou outros imprevistos durante as festividades. O dono/presidente do maracatu é o responsável por intermediar a relação entre os folgazões e os padrinhos espirituais. O preparo inclui resguardo sexual, banhos à base de ervas, orações, aguações, fumaças de cachimbo e charuto, matança de animais, velas, etc. (FUNDARPE, 2013, p. 75).

Além das pessoas, a proteção espiritual se destina também a determinados objetos, notadamente a bengala do mestre do apito, o cravo que vai na boca do caboclo de lança e a Calunga (boneca) da Dama do Paço. Detalhes sobre rituais de "calço" desses objetos não são revelados. $\mathrm{Na}$ verdade, observa-se que apenas o interdito sexual é assunto tornado mais corrente. Ele consiste na proibição que os folgazões têm de manterem relações sexuais alguns dias antes e durante o carnaval (FUNDARPE, 2013, p. 76).

Nesse aspecto religioso, convém que todo grupo de maracatu tenha seu padrinho ou madrinha, que pode ser um pai-de-santo ou uma mãe-de-santo, ou outra autoridade religiosa. Eles é que executam os "trabalhos" religiosos, em locais que variam da sede do maracatu à casa do dono/presidente do grupo, em terreiros (diante dos pejis) e também em lugares abertos, como encruzilhadas. Tanto o local quanto o trabalho a ser feito vai depender da finalidade do serviço, do objetivo que se quer buscar (FUNDARPE, 2013, p. 77). Não existe período do ano certo para a realização dos rituais, embora o mês preferencial para muitas seja o de agosto, conforme o INRC do Maracatu de Baque Solto (idem, 2013, p. 82). Isso envolve também a rivalidade dos grupos, que se expressa religiosamente em rituais das "linhas de esquerda". Conforme Maria Alice Amorim (FUNDARPE, 2013, p. 77):

Os rituais realizados em cemitérios, ou encruzilhadas, são aqueles chamados pelos adeptos das religiões afro-brasileiras de “rituais de esquerda”. Podem ser oferendas a orixás como Exu, Pomba-Gira (Exu fêmea), Iansã de Balé (Iansã de Cemitério) ou a Mestres como, por exemplo, Vira Mundo e Malunguinho. Os preparos de cemitério podem indicar a rivalidade existente entre grupos.

\section{CONSIDERAÇões FINAIS}

O processo de patrimonialização do Maracatu de Baque Solto, em seu objetivo de classificá-lo como Forma de Expressão para fins de reconhecimento patrimonial, revela, por outrolado, que o bem opera aspectos culturais diversificados em uma consolidada rede de sentidos. O bem cultural, como realizado pelos detentores, possui muito mais nuances e sentidos, articulando uma complexa rede de relações sociais não percebidas pelo público que o vislumbra nas apresentações do carnaval. Visto por eles como "brincadeira", "folguedo", "brinquedo", após o processo de Registro - com suas etapas de pesquisa, mobilização social, e todo o rito 
burocrático e político para o reconhecimento por parte do Estado - o maracatu torna-se "patrimônio cultural imaterial”, mediante o título de Patrimônio Cultural do Brasil conferido pelo IPHAN com base no Decreto $\mathrm{n}^{\circ} 3.551 / 2000$.

Para botar um maracatu na rua, é necessário sacrifício: seja de tempo, diante da temporalidade e das obrigações do labor do dia a dia, formal ou não; seja da renda, diante das necessidades de sustento próprio e da família; seja do trabalho, diante da dinâmica de manutenção do bem cultural. Botar um maracatu na rua envolve paixão. Esta é sentida desde a infância, e acompanha a vida dos sujeitos no espaço e no tempo. Agora, o Estado ao reconhecer o maracatu como parte constitutiva do patrimônio cultural brasileiro, soma-se a esses esforços e, também, ao amor dos detentores para a manutenção da tradição.

\section{REFERÊNCIAS}

Barbosa, Virgínia (2018). Caboclo de Lança. Fundação Joaquim Nabuco, Recife. Recuperado em em 27 ago. 2021 h ttps://pesquisaescolar.fundaj.gov.br/pt-br/artigo/caboclo-de-lanca/

Brasil (2000). Decreto no 3.551, de 4 de agosto de 2000. Institui o Registro de Bens Culturais de Natureza Imaterial que constituem patrimônio cultural brasileiro, cria o Programa Nacional do Patrimônio Imaterial e dá outras providências. Recuperado em 21 ago. 2021. http://www.planalto.gov.br/ccivil_03/decreto/d3551.htm

Esteves, Leonardo Leal (2016a). “Cultura” e burocracia: as relações dos Maracatus de Baque Solto com o Estado. Tese de Doutorado. Programa de Pós-Graduação em Antropologia. Recife: UFPE.

Esteves, Leonardo Leal (2016b). O Maracatu de Baque Solto e o Estado: desafios para a salvaguarda de um "brinquedo pesado". Recuperado em 8 fev. 2018.

Fundação do Patrimônio Histórico e Artístico de Pernambuco (FUNDARPE) (2013) INRC do Maracatu de Baque Solto: Dossiê de candidatura.

Instituto do Patrimônio Histórico e Artístico Nacional (IPHAN) (2006). O Registro do patrimônio imaterial: dossiê final das atividades da Comissão e do Grupo de Trabalho Patrimônio Imaterial. 4. ed.

Lemos, Flávia Cristina Silveira; Galindo, Dolores; Zanella, Andrea; Bengio, Fernanda Cristine Santos; Assis, Neiva de (2018). Políticas de patrimonialização e produção de subjetividades ao sul do Brasil. Rev. psicol. polít., São Paulo, v. 18, n. 41, p. 07-17. Recuperado em 10 ago. 2021. http://pepsic.bvsalud.org/scielo.php?script=sci_art text\&pid=S1519-549X2018000100002\&lng=pt\&nrm=iso

Martins, Carla Pires (2013) Cravo do Canavial: 'entre' o maracatu rural e a mímesis corpórea: a construção de uma dramaturgia cênica. Dissertação de Mestrado. Universidade Federal do Rio Grande do Norte. Centro de Ciências Humanas, Letras e Artes. Programa de Pós-Graduação em Artes Cênicas.

Medeiros, Roseana Borges de (2003). Maracatu Rural: luta de classes ou espetáculo? (um estudo das expressões de resistência, luta e passivização das classes subalternas). Tese de Doutorado. Programa de Pós-Graduação em Serviço Social. Recife: UFPE.

Romero, Fernanda Gabriela Gadelha (2014). O ativismo midiático e a apropriação do maracatu rural Estrela de Ouro de Aliança - PE pelo mercado cultural. Dissertação de Mestrado. Programa de Pós-Graduação em Comunicação. João Pessoa: UFPB.

Sena, José Roberto Feitosa de (2014). Apontamentos histórico-sociológicos do Maracatu de Baque Solto no carnaval popular e institucionalizado do Recife/PE. II Encontro Internacional História, Memória, Oralidade e Culturas, Fortaleza/CE.

Silva, Giorge Patrick Bessoni e (2020). O que eu ganho com isso? Desafios da sustentabilidade econômica do patrimônio imaterial a partir do Maracatu de Baque Solto. Dissertação de Mestrado. Instituto do Patrimônio Histórico e Artístico Nacional. Rio de Janeiro: IPHAN.

Silva, Severino Vicente da (2012). Festa de caboclo. Olinda: Associação Reviva.

Silva, Noshua Amoras de Morais e (2015). Manobras e evoluções: etnografia dos movimentos do Maracatu Leão de Ouro de Condado (PE). Monografia de Graduação. Departamento de Antropologia. Brasília: UnB. 
Silva, Sandra Siqueira da (2011). Patrimonialização da cultura como forma de desenvolvimento: considerações sobre as teorias do desenvolvimento e o patrimônio cultural. Recuperado em 10 ago. 2021. https://www.marilia.une sp.br/Home/RevistasEletronicas/Aurora/9silva106a113.pdf

Vieira, Sévia Sumaia (2003). Dos Canaviais à Capital: cabocarias de Flecha, maracatus de orquestra, baque solto, rural... Dissertação de Mestrado. Programa de Pós-Graduação em Antropologia. Recife: UFPE.

Vieira, Sévia Sumaia; Silva, João Marcelo (2007). Caboclo de lança: imaginário, identidade e narrativa social. III Congresso Brasileiro de Sociologia, Recife/PE.

\section{Notas}

[1]O presente artigo parte do texto do Capítulo 2 da dissertação de minha autoria, defendida em 2020 no Programa do Mestrado Profissional em Preservação do Patrimônio Cultural do IPHAN, intitulada "O que eu ganho com isso? Desafios da sustentabilidade econômica do patrimônio imaterial a partir do Maracatu de Baque Solto”.

[2] Outros trabalhos relevantes como o de Sévia Sumaia Vieira (2003), trazem aspectos etnográficos e reflexões sobre a produção e a reprodução cultural de grupos de maracatu de baque solto.

[3]Trata-se do Inventário Nacional de Referências Culturais - INRC do Maracatu de Baque Solto, pesquisa contratada pela Fundação do Patrimônio Histórico e Artístico de Pernambuco, autarquia vinculada à Secretaria de Cultura do Estado de Pernambuco (Fundarpe/Secult/PE), que realizou, entre os anos de 2011 e 2013, inventário cultural, pesquisa histórica e etnografia de 93 (noventa e três) grupos de Maracatu de Baque Solto na Zona da Mata Norte do estado e na Região Metropolitana do Recife, portanto uma significativa parcela do total de grupos hoje existentes.

[4]Conforme exigências do Iphan, o Dossiê de Registro deve, necessariamente, conter: descrição e contextualização do bem cultural com aspectos históricos e culturais relevantes; justificativa para o Registro; e recomendações para a salvaguarda do bem (IPHAN, 2006).

[5]A pesquisa foi contratada pela Fundação do Patrimônio Histórico e Artístico de Pernambuco (FUNDARPE), por ocasião da instrução técnica do processo de Registro do maracatu de baque solto no âmbito do Iphan. Foi realizada com base no Inventário Nacional de Referências Culturais (INRC), método de sistematização de dados de bens culturais disponibilizado pelo Iphan desde o ano 2000. Teve a renomada pesquisadora Maria Alice Amorim como coordenadora de uma equipe multidisciplinar, que contou com historiadores, antropólogos, fotógrafos, videastas, dentre outros.

[6]Cf. o processo administrativo do Iphan $n^{\circ}$ 01450.010231/2008-51, no Sistema Eletrônico de Informações - SEI, no site www.sei.iphan.gov.br, que permite consulta pública de processos administrativos.

[7]Cabe ressaltar que um dos Livros de Registro instituídos pelo Decreto no 3.551/2000 é o Livro de Registro das Celebrações. Segundo o Decreto, em seu Artigo $1^{\circ}$, inciso II, neste livro são inscritos "rituais e festas que marcam a vivência coletiva do trabalho, da religiosidade, do entretenimento e de outras práticas da vida social” (Brasil, 2000).

[8]Cf. processo administrativo no 01450.010231/2008-51 (Disponível em http://sei.iphan.gov.br). Documentos relevantes do processo de Registro do Maracatu de Baque Solto encontram-se disponíveis em http://portal.iphan.gov.br/pagina/detalhes/505/.

[9] O mestre do apito é de fácil identificação na brincadeira. É ele quem entoa a poesia do maracatu, na maioria das vezes em versos de improviso, e está sempre acompanhado de seus instrumentos de trabalho: a bengala (cheia de anéis e brilhantes) e, é claro, o apito. Tais instrumentos são poderosos objetos rituais para os folgazões e maracatuzeiros, nos quais não é permitido a qualquer pessoa tocar.

[10]Caboclos de lança experientes conseguem reconhecer outro caboclo pelo som do surrão!

[11]A boneca calunga é trabalhada espiritualmente para desfilar com o grupos. Segundo Sena (2014) "Nos meses prévios [ao carnaval], inicia-se um trabalho de preparação (...), onde a calunga recebe todas as energias, passando a ser o elemento central da simbologia ritualística do Maracatu".

[12]Personagem cômico, rosto pintado de preto, apresenta-se com roupas simples - camisa estampada, calça e sapato. Está presente em outros folguedos da cultura popular brasileira, como o Cavalo Marinho e a Folia de Reis, fazendo as vezes de negro alegre diante das adversidades da vida (FRANCO, 2012). O par Mateus e Catirina são palhaços da cultura brasileira. Ressalte-se que a Catita também é chamada de Catirina por alguns folgazões de baque solto. 
[13]Há quem suponha que o termo “poica” seja uma pronúncia de “porca”, visto que a cuíca tocada no Maracatu de Baque Solto produz um som que remete ao grunhido de um porco.

[14]Para descrição detalhada dos aspectos musicais e sonoros do Maracatu de Baque Solto, ver FUNDARPE, 2013.

[15]Em conversa informal com um detentor, e importante interlocutor para esta pesquisa, ele disse, literalmente: "O que o turista vê no carnaval é só dez por cento do que é o maracatu”.

[16] Neste caso não se faz referência aos terreiros religiosos, como os de Candomblé ou de Catimbó. No contexto do maracatu de baque solto, terreiros são os espaços onde se situam os maracatus (grupos), seja sua sede, ou o engenho, ou o sítio que o abriga. 